\title{
Effect of Rotational Speed on Linear and Non-Linear Optical Properties of Sol-Gel Spin Coated Nanostructured CdS Thin Films
}

\author{
M. Venkata Veera Prasad1,*, K. Thyagarajan², B. Rajesh Kumar³ \\ ${ }^{1}$ Department of Physics, JNTU Anantapur, Anantapuramu - 515 002, Andhra Pradesh, India \\ ${ }^{2}$ Department of Physics, JNTUA College of Engineering, Pulivendula - 516 390, Andhra Pradesh, India \\ ${ }^{3}$ Department of Physics, GITAM (Deemed to be University), Visakhapatnam - 530 045, Andhra Pradesh, India.
}

\section{A R T I C L E D E T A I L S}

Article history:

Received 20 April 2019

Accepted 06 May 2019

Available online 18 May 2019

\section{Keywords:}

Sol-Gel Spin Coating

CdS Thin Film

Electrical Properties

Optical Properties

\begin{abstract}
A B S T R A C T
Cadmium sulfide thin films have been prepared by sol-gel spin coating method on glass substrates at different rotational speeds. Glancing angle X-ray diffraction patterns of CdS thin films exhibit cubic phase with $\left(\begin{array}{lll}1 & 1 & 1\end{array}\right)$ as preferential orientation. The surface morphology of the CdS thin films was studied by atomic force microscope. The electrical resistivity of CdS thin films decreased from $5.66 \times 10^{3}$ to $1.72 \times$ $10^{3} \Omega$.cm with the increase of rotational speed from 1500 to $3000 \mathrm{rpm}$. The optical transmittance of CdS thin films increased because of reduction in film thickness with the increase of rotational speed. The optical band gap of CdS thin films decreased from 2.65 to $2.46 \mathrm{eV}$ with the increase of rotational speed due to quantum confinement effect. The normal dispersion of refractive index for CdS thin films is described using Wemple-DiDomenico single-oscillator model. The optical dispersion parameters such as single-oscillator energy $\left(E_{o}\right)$, the dispersion energy $\left(E_{d}\right)$ and the static refractive index $n_{o}$ were calculated. The Verdet coefficient $(V)$ is determined based on the refractive index dispersion study. The first and third order nonlinear optical susceptibility $\left(\chi^{(1)}, \chi^{(3)}\right)$, nonlinear refractive index $\left(n_{2}\right)$ are determined for CdS thin films.
\end{abstract}

\section{Introduction}

Cadmium sulfide (CdS) belongs to II-VI semiconducting material with a direct band gap of $2.42 \mathrm{eV}$ (in cubic phase) and $2.57 \mathrm{eV}$ (in hexagonal phase) at room temperature. CdS exhibit in two forms namely $\alpha$-CdS (hexagonal wurtzite, space group: $\mathrm{P}_{3} \mathrm{mc}$ ) and $\beta$-CdS (cubic, zinc blende crystal structure, space group: F- $43 \mathrm{~m}$ ). $\beta$-CdS forms at low temperature with a metastable phase where as $\alpha$-CdS forms at high temperatures with a stable phase; however, annealing at high temperatures $\beta$-CdS can transform to $\alpha$-CdS [1]. CdS had a bulk refractive index of 2.52 at wavelength $600 \mathrm{~nm}$ which is well suited for solar cell applications [2]. Cadmium sulfide (CdS) is most widely used in heterojunction thin-film photovoltaics as a window layer in CdTe thin-film solar cells and as a buffer layer in $\mathrm{Cu}(\mathrm{In}, \mathrm{Ga}) \mathrm{Se}_{2}$ (CIGS) thin-film solar cells. CdS most widely found applied material in electro-optic devices such as photoconducting cells, photosensors, transducers, optical wave-guides and non-linear integrated optical devices, diluted magnetic semiconductors in spintronic devices, light emitting diodes, field effect transistors and gas sensors [3-7].

CdS thin films has been prepared by different workers using different methods which includes pulsed laser deposition (PLD) [8], sputtering [9], thermal evaporation [10], metal organic chemical vapor deposition (MOCVD) [11], chemical bath deposition (CBD) [12], layer adsorption and reaction (SILAR)[13], spray pyrolysis [14] and sol-gel route [15] . Each method produces the films with different physical properties, which should be optimized for specific applications. Among these methods, the sol-gel spin coating method is a simple, low cost, and ability to produce uniform films with good adherence, provides a high specific surface area, narrow pore size, better microstructural control of metallic particles and uniform particle distribution [16]. Many researchers reported the structural, electrical and optical properties of CdS thin films. Studies on the nonlinear optical properties of sol-gel spin coated CdS thin films are very rare to find in the literature. The main objective of this paper is to study the effect of rotational speed on the linear and non-linear optical properties of $\mathrm{CdS}$ thin films and to report the detailed information on

optical constants, optical dispersion parameters and non-linear optical parameters which are of considerable importance for its applications in integrated optical devices such as switches, filter, modulators, etc.

\section{Experimental Methods}

CdS thin films have been prepared by mixing $0.6 \mathrm{~mL}$ of polyethylene glycol (PEG 200) with $8.9 \mathrm{~mL}$ of ethanol and $0.5 \mathrm{~mL}$ of acetic acid under stirring continuously for 90 minutes. Cadmium nitrate $\left(\mathrm{Cd}\left(\mathrm{NO}_{3}\right)_{2} .4 \mathrm{H}_{2} \mathrm{O}\right)$ and thiourea $\left(\mathrm{SC}\left(\mathrm{NH}_{2}\right)_{2}\right)$ (chemicals of analytical grade from Sd Fine Chem. Pvt. Ltd., Mumbai, India) were used as precursors for cadmium and sulfur source. These precursors were dissolved in an ethanol with stirring for 90 minutes. The as-prepared solution was slowly added to PEG sol with stirring for 6 hours in order to obtain the final sol, which is used for depositing CdS thin films. The spin coating method was used to deposit $\mathrm{CdS}$ thin films using the above sol on glass substrates. The glass substrates were cleaned thoroughly with detergent laboline and then rinsed with double distilled water. Then the substrates were kept in concentrated chromic acid for 12 hours. After chromic acid treatment, the substrates were cleaned ultrasonically in double distilled water and acetone for 10 min. Finally, the substrates were dried under an infra-red (IR) lamp. These glass substrates were used for the preparation of CdS thin films. CdS thin films were prepared on glass substrates by spin coating method with varying rotational speed from 1500 to $3000 \mathrm{rpm}$ and annealed in vacuum at $200{ }^{\circ} \mathrm{C}$. The thickness of the $\mathrm{CdS}$ thin films was measured by using Talysurf thickness profilometer.

Structural properties of CdS thin films were analyzed by Glancing angle X-ray diffraction (GAXRD) using a Rigaku X-ray diffractometer with a CuKa radiation $(\lambda=0.154 \mathrm{~nm})$ source operated at $40 \mathrm{kV}$ and $40 \mathrm{~mA}$. X-ray diffraction measurements were recorded in the $2 \theta$ range of $20^{\circ}-90^{\circ}$ at a glancing angle of $2^{\circ}$ with a scan speed of $1^{\circ} \mathrm{min}^{-1}$. The surface morphology of the CdS thin films was studied by using atomic force microscope (AFM; Model: Park NX20). The thickness of the CdS films is measured by Dektak surface profilometer. The electrical measurements of CdS thin films were carried out by four-probe method and Hall effect setup. The optical transmittance spectra of the CdS thin films were recorded by using UV-VisNIR spectrometer (Shimadzu MPC3600) in the wavelength range of 300$2500 \mathrm{~nm}$. 


\section{Results and Discussion}

\subsection{Structural Analysis}

Glancing angle X-ray diffraction (GAXRD) patterns of CdS thin films prepared by sol-gel spin coating method on glass substrates by varying rotational speeds from 1500 to $3000 \mathrm{rpm}$ are shown in Fig. 1. The diffraction peaks for CdS thin films are indexed to (llll), (l $\left.\begin{array}{lll}2 & 2 & 0\end{array}\right)$ and (3 1 1) planes of pure CdS (JCPDS Card No. 10-0454). It is noticed that all the films exhibit (1 111 ) preferred orientation with a cubic structure.

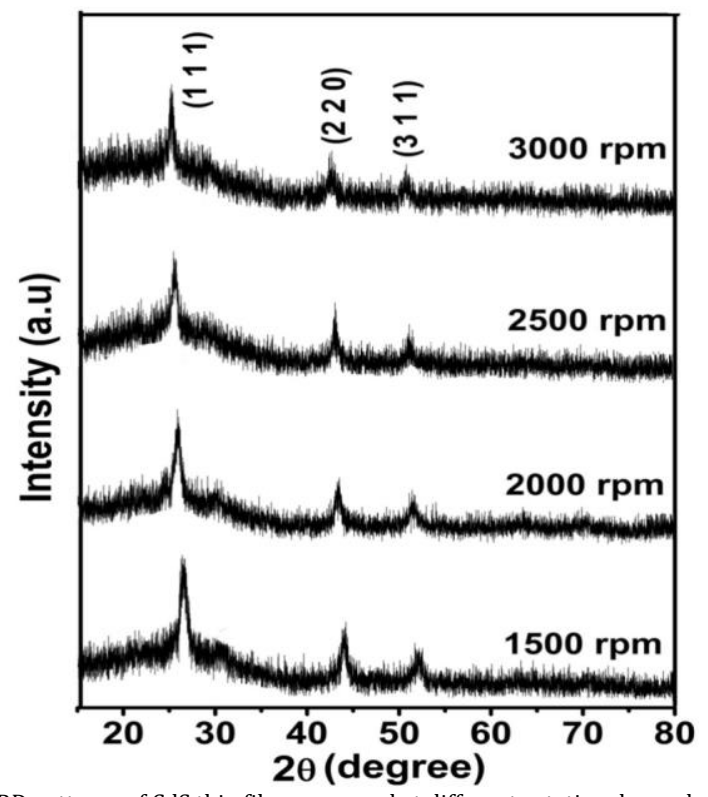

Fig. 1 XRD patterns of CdS thin films prepared at different rotational speeds

The $2 \theta$ value of $\left(\begin{array}{lll}1 & 1 & 1\end{array}\right)$ diffraction peak shifts towards the lower angle with the increase of rotational speed owing to increase in the lattice constant. The full width at half maxima (FWHM) of the diffraction peak decreased from 0.325 to $0.205^{\circ}$ with the increase of rotational speed. The decrease of FWHM leads to an increase in crystallite size for CdS thin films. The interplanar spacing $(d)$ corresponding to $\left(\begin{array}{lll}1 & 1 & 1\end{array}\right)$ plane for CdS thin films is calculated using the Bragg's equation,

$$
2 d \sin \theta=n \lambda
$$

where $\theta$ is Bragg angle, $\lambda$ is the wavelength of X-ray $(=0.154 \mathrm{~nm})$ and $n$ is an integer. The interplanar spacing of CdS thin films increases from 0.3356 to $0.3376 \mathrm{~nm}$ with the increase of rotational speed. The lattice constant $(a)$ of CdS thin films was calculated from the formula,

$$
a=d\left(h^{2}+k^{2}+l^{2}\right)^{1 / 2}
$$

For the observed d values corresponding to $(h k l)$ plane obtained by Xray diffraction data. The lattice constant $(a)$ values increases from 0.5813 to $0.5788 \mathrm{~nm}$ with the increase of rotational speed from 1500 to $3000 \mathrm{rpm}$. The increase of interplanar spacing and lattice constant with the increase of rotational speed may be due to the shift of the angular position of (1 1 1) plane towards higher angle side. The crystallite size $(D)$ of CdS thin films is estimated from the Scherer's formula [17]. Its value increased from 26.23 to $41.58 \mathrm{~nm}$ which results in the decrease of grain boundary leading to higher conductivity in the films

Table 1 Structural parameters of CdS thin films prepared at different rotational speeds

\begin{tabular}{lllllll}
\hline $\begin{array}{l}\text { Rotational } \\
\text { speed } \\
(\mathrm{rpm})\end{array}$ & $\begin{array}{l}2 \theta \\
\left.{ }^{\circ}\right)\end{array}$ & $\begin{array}{l}\text { FWHM } \\
\left.{ }^{\circ}\right)\end{array}$ & $\begin{array}{l}\mathrm{d}- \\
\text { spacing } \\
(\mathrm{nm})\end{array}$ & $\begin{array}{l}\text { Lattice } \\
\text { constant, } \\
\mathrm{a}(\mathrm{nm})\end{array}$ & $\begin{array}{l}\text { Crystallite } \\
\text { size, } \\
\mathrm{D}(\mathrm{nm})\end{array}$ & $\begin{array}{l}\text { Number of } \\
\text { crystallites, } \\
\mathrm{N} \mathrm{x} \mathrm{1015}\left(\mathrm{m}^{-2}\right)\end{array}$ \\
\hline 1500 & 26.54 & 0.325 & 0.3356 & 0.5813 & 26.23 & 11.08 \\
2000 & 26.48 & 0.284 & 0.3364 & 0.5826 & 30.02 & 7.39 \\
2500 & 26.44 & 0.232 & 0.3369 & 0.5835 & 36.74 & 4.03 \\
3000 & 26.38 & 0.205 & 0.3376 & 0.5848 & 41.58 & 2.78 \\
\hline
\end{tabular}

The number of crystallites per unit area $(N)$ is calculated by using the formula,

$$
N=\frac{t}{D^{3}}
$$

where $t$ is the film thickness and $D$ is the crystallite size. The thickness of the films measured from surface profilometer decreased from 320 to 180 https://doi.org/10.30799/jnst.238.19050210 $\mathrm{nm}$ with the increase of rotational speed. It is due to the fact that an increase in rotation speed increases the centrifugal force on the deposition solution on the substrate which makes the film thin. The number of crystallites $(N)$ of CdS thin films decreases from $11.08 \times 10^{15}$ to $2.78 \times 10^{15}$ $\mathrm{m}^{-2}$ with the increase of rotational speed. The structural parameters of CdS thin films post-annealed at different temperatures are shown in Table 1.

\subsection{AFM Analysis}

Fig. 2 shows the AFM images (scan area of $2 \mu \mathrm{m} \times 2 \mu \mathrm{m}$ ) for CdS thin films taken in non-contact mode. From AFM images, it is observed that the grain size increases with the increase of rotational speed due to the increase in grain boundary movement and mobility of the thin films. The average roughness $\left(R_{a}\right)$ of the CdS thin films increased from 8.9 to $23.4 \mathrm{~nm}$, whereas the RMS roughness $\left(R_{q}\right)$ values increased from 6.6 to $18.5 \mathrm{~nm}$ with the increase of rotational speed from 1500 to $3000 \mathrm{rpm}$. The increase in surface roughness of the films decreases the reflective loss which consequently increases the quantum efficiency of a solar cell [18]. The maximum peak height $\left(R_{p}\right)$ and peak valley $\left(R_{z}\right)$ values increased with the increase of rotational speed due to the improvement in crystallinity of the films. The negative values of skewness $\left(R_{s k}\right)$ indicate that the film had a rough surface with a low density of dips or valleys and flat regions. When kurtosis $\left(R_{k u}\right)$ value is equal to 3 , it represents the surface with a Gaussian height distribution and the surface is called Mesokurtic, but if $R_{k u}<3$ the surface is flat and called Platykurtic. If $R_{k u}>3$, the surface has more number of peaks than valleys. The CdS thin films exhibit the value of $R_{k u}>3$ and the distribution will have a relatively higher number of peaks and low valleys with a spiky surface. The statistical analysis of CdS thin films obtained from AFM is given in Table 2.
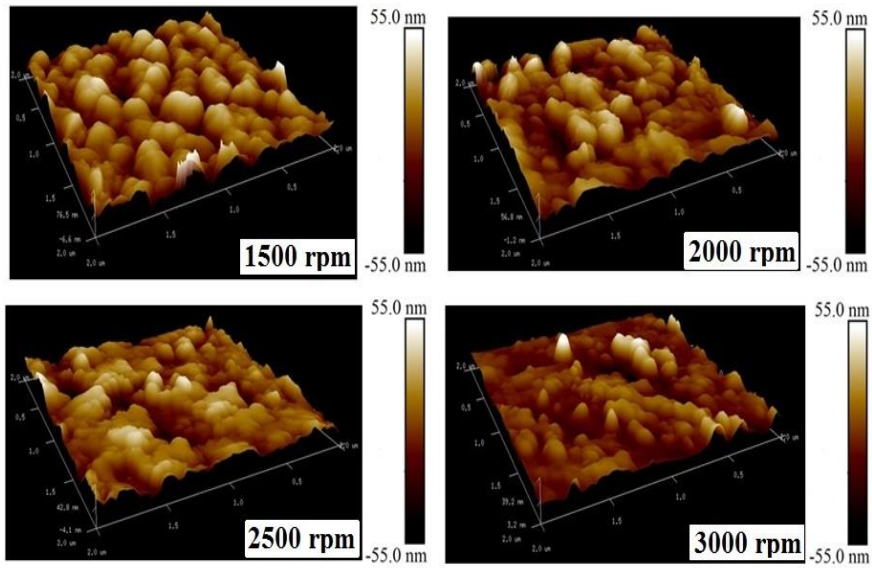

Fig. 2 AFM images of CdS thin films prepared at different rotational speeds

Table 2 Surface roughness parameters of CdS thin films

\begin{tabular}{llllllll}
\hline $\begin{array}{l}\text { Rotational speed } \\
(\mathrm{rpm})\end{array}$ & $\begin{array}{l}\mathrm{R}_{\mathrm{a}} \\
(\mathrm{nm})\end{array}$ & $\begin{array}{l}\mathrm{R}_{\mathrm{q}} \\
(\mathrm{nm})\end{array}$ & $\begin{array}{l}\mathrm{R}_{\mathrm{z}} \\
(\mathrm{nm})\end{array}$ & $\begin{array}{l}\mathrm{R}_{\mathrm{p}} \\
(\mathrm{nm})\end{array}$ & $\begin{array}{l}\mathrm{R}_{\mathrm{v}} \\
(\mathrm{nm})\end{array}$ & $\mathrm{R}_{\mathrm{sk}}$ & $\mathrm{R}_{\mathrm{ku}}$ \\
\hline 1500 & 8.9 & 6.6 & 12.6 & 18.8 & -20.4 & -0.138 & 4.14 \\
2000 & 12.5 & 9.6 & 16.1 & 20.8 & -21.8 & -0.501 & 3.85 \\
2500 & 16.7 & 13.2 & 33.9 & 24.4 & -32.4 & -0.402 & 3.04 \\
3000 & 23.4 & 18.5 & 54.6 & 27.8 & -36.7 & -0.396 & 3.24 \\
\hline
\end{tabular}

\subsection{Electrical Properties}

The electrical resistivity $(\rho)$ of the CdS thin films were measured by using a four-probe method. The electrical resistivity of CdS thin films decreased from $5.66 \times 10^{3}$ to $1.72 \times 10^{3} \Omega \mathrm{cm}$ with the increase of rotational speed from 1500 to $3000 \mathrm{rpm}$. The decrease in electrical resistivity of the CdS thin films is due to the decrease in the density of grain boundary intercrystallites and defects such as pinholes, voids etc. The obtained electrical resistivity values are in good agreement with previously reported works $[19,20]$. The carrier concentration $\left(n_{c}\right)$ and mobility $\left(\mu_{H}\right)$ of the CdS thin films were obtained from Hall effect measurements at room temperature in a magnetic field of $0.35 \mathrm{~T}$ [21]. The sign of Hall voltage across the samples is negative, which indicates an n-type semiconducting behavior of the films. The carrier concentration of CdS thin films increased from $0.88 \times 10^{13}$ to $1.36 \times 10^{13} \mathrm{~cm}^{-3}$ with the increase of rotational speed from 1500 to $3000 \mathrm{rpm}$. The increase in the carrier concentration of the films causes shrinkage in the gap known as the bandgap narrowing, which signifies that the density of dislocations and density of grain boundaries will be decreased [22]. The carrier concentration is in the order of $10^{13} \mathrm{~cm}^{-}$ 3 for all the films and these values are in good agreement with chemical bath deposited CdS thin films $[23,24]$. The Hall mobility of the films increased from 125 to $265 \mathrm{~cm}^{2} \mathrm{~V}^{-1} \mathrm{~s}^{-1}$ with the increase of rotational speed from 1500 to $3000 \mathrm{rpm}$ due to the increase in the grain size and reducing 
grain boundary scattering. The mean free path $(L)$ of an electron is calculated using the equation [25],

$$
L=\left(3 \pi^{2}\right)^{1 / 3}\left(h / 2 \pi e^{2}\right) \cdot 1 / \rho \cdot n_{c}^{2 / 3}
$$

where $h$ is Planck's constant, $e$ is the electron charge, $\rho$ is the resistivity, and $n_{c}$ is the carrier concentration. The calculated mean free path $(L)$ of an electron of CdS thin films varies from 4.76 to $11.70 \mathrm{~nm}$. The obtained values of mean free path are much shorter than the grain size measured according to XRD analysis. They reported that the effect of scattering at grain boundaries and dislocations can be neglected when the mean free path is smaller than the grain size, and concluded that scattering of conduction electrons depends on neutral and ionized impurities. The electrical properties of CdS thin films prepared with different rotational speeds are given in Table 3.

Table 3 Electrical properties of CdS thin films prepared by varying rotational speeds

\begin{tabular}{llllll}
\hline $\begin{array}{l}\text { Rotational } \\
\text { speed } \\
(\mathrm{rpm})\end{array}$ & Type & $\begin{array}{l}\text { Electrical } \\
\text { resistivity, } \\
\rho(\Omega . \mathrm{cm})\end{array}$ & $\begin{array}{l}\text { Carrier } \\
\text { concentration, } \\
\mathrm{n}_{\mathrm{c}} \times 10^{13}\left(\mathrm{~cm}^{-3}\right)\end{array}$ & $\begin{array}{l}\text { Hall- } \\
\text { mobility, } \\
\mu_{\mathrm{H}}\left(\mathrm{cm}^{2} \mathrm{~V}^{-1} \mathrm{~S}^{-1}\right)\end{array}$ & $\begin{array}{l}\text { Mean free } \\
\text { path, } \\
\mathrm{L}(\mathrm{nm})\end{array}$ \\
\hline 1500 & $\mathrm{n}$ & $5.66 \times 10^{3}$ & 0.88 & 125 & 4.76 \\
2000 & $\mathrm{n}$ & $4.64 \times 10^{3}$ & 0.95 & 141 & 5.52 \\
2500 & $\mathrm{n}$ & $3.30 \times 10^{3}$ & 1.13 & 167 & 6.94 \\
3000 & $\mathrm{n}$ & $1.72 \times 10^{3}$ & 1.36 & 265 & 11.70 \\
\hline
\end{tabular}

\subsection{Optical Properties}

\subsubsection{Optical Transmittance and Energy Band Gap}

The optical transmittance spectra of CdS thin films prepared with different rotational speeds are shown in Fig. 3(a). The shift of absorption edge towards longer wavelengths with an increase in rotational speed indicates the growth of the particles on annealing. The average optical transmittance of CdS thin films (in the UV-Vis region) increased from 72 to $90 \%$ with the increase of rotational speed which may be caused by lattice imperfections, reduction in voids, film thickness and increase in the crystallite size. Furthermore, the films revealed high transparency in the visible range, $T(\lambda)>70 \%$ makes useful as a transparent electrode for optoelectronic devices. Fig. 3(b) shows the extrapolation of $(\alpha h v)^{2}$ versus $h v$, with the intercept of the straight line on $h v$ axis the optical band gap of CdS thin films were determined. The optical band gap of CdS thin films decreased from 2.65 to $2.46 \mathrm{eV}$ with the increase of rotational speed from 1500 to $3000 \mathrm{rpm}$ due to quantum size confinement effect. The obtained direct band gap values are in good agreement with the previously reported values for cubic CdS thin films [26, 27]. The optical constants of CdS thin films were calculated from the equations as reported in the earlier literature $[28,29]$. The absorption coefficient $(\alpha)$ values of $\mathrm{CdS}$ thin films prepared at different rotational speeds are in the range of $1.23 \times 10^{4}-4.87$ $\times 10^{4} \mathrm{~cm}^{-1}$. The variation of extinction coefficient $(k)$ for CdS thin films as a function of wavelength is shown in Fig. 3(c).
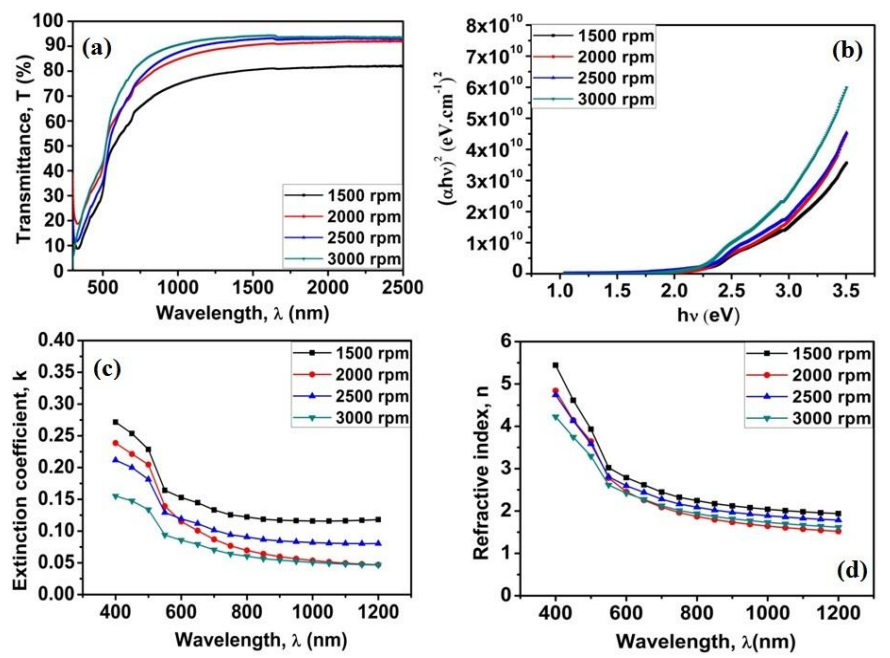

Fig. 3 Variation of (a) Optical transmittance spectra versus wavelength; (b) Tauc's plot for CdS thin films; (c) Extinction coefficient, $\mathrm{k}$ and (d) Refractive index, $\mathrm{n}$ for CdS thin films as a function of wavelength

The extinction coefficient values are in the range of 0.046 - 0.155 , whose values decreases with the increase of wavelength. The low values of the extinction coefficient for the CdS films in the visible and near infrared region show their surface smoothness and high optical transmittance. The https://doi.org/10.30799/jnst.238.19050210 optical band gap of the CdS thin films was determined by using the Tauc's formula [30,31]. The variation of refractive index $(n)$ with wavelength for CdS thin films prepared with different rotational speeds is shown in the Fig. 3(d). The refractive index $(n)$ of the films decreased from 2.78 to 2.42 (at wavelength $600 \mathrm{~nm}$ ) with the increase of rotational speed from 1500 to $3000 \mathrm{rpm}$ due to the improvement in crystallinity of the films. At the shorter wavelengths, the refractive index value increases rapidly and at energies lower than absorption edge, its value falls down and saturates at higher wavelength representing the normal dispersion behaviour which can be explained in terms of single oscillator model. It is also clear that, the effect of rotational speed on the refractive index and semiconductor dispersion profiles exhibit a linear displacement in the dispersion profile with decreasing refractive index. The refractive index of the films declines towards longer wavelengths which may be due to the influence of lattice absorption. H. Metin et al. [32] reported similar behavior in the change of refractive index for the $\mathrm{CdS}$ thin films prepared by the chemical deposition method.

\subsubsection{Optical Dispersion, Group and Phase Velocity}

The optical dispersion is an important parameter to understand the optical properties of the films. Fig. 4(a)-(c) shows the optical dispersion, group and phase velocity of films with photon wavelength respectively. It is seen that optical dispersion $d n / d \lambda$ of the film depends on both rotational speed and wavelength. The group velocity, $U_{g}$ describing pulse propagation through an isotropic medium with undistorted shape is expressed as [33],

$$
U_{g}=d \omega / d k=c /[n-\lambda(d n / d \lambda)]
$$

where $c$ is the velocity of light in vacuum, $k$ is the wave number, $\omega$ is the angular frequency of the incident light. The wavelength of dependence of the group velocity and phase velocity for the CdS thin film is shown in Fig. 4(b) and 4(c). The results show that the group velocity and phase velocity for CdS thin films increases with wavelength, but decreases with rotational speed which may be due to the optical dispersion in the material.

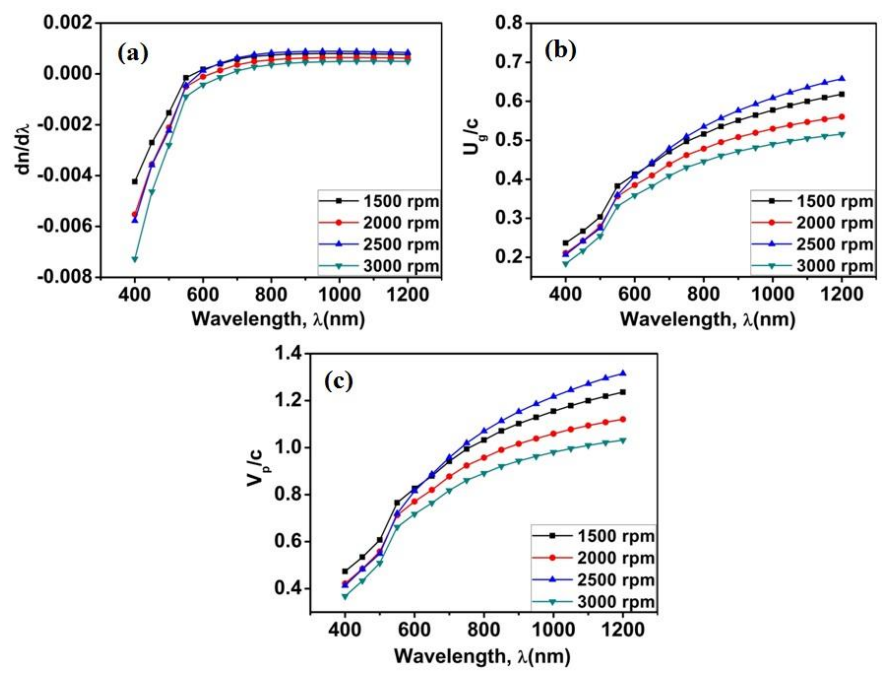

Fig. 4 Variation of (a) optical dispersion, $d n / d \lambda$; (b) group velocity, $U_{g} / c$ and (c) phase velocity, $v_{\mathrm{p}} / \mathrm{c}$ of $\mathrm{CdS}$ thin films as a function of wavelength

\subsubsection{Magneto-Optical Constant: Verdet Coefficient (V)}

The Verdet coefficient $(V)$ is known as the single pass volume Faraday rotation per unit magnetic field and unit thickness. The Verdet coefficient is normally measured using two Glan-Taylor polarizers, but in the present study we estimated it from the refractive index dispersion [34]. The refractive index is related to $V$ as follows,

$$
V(\lambda)=\mu_{o} \cdot r \cdot(e / 2 m c) \cdot \lambda \cdot d n / d \lambda
$$

where $\mu_{o}$ is the vacuum permeability, $r$ is the magneto-optical anomaly factor which is close to 0.28 for materials exhibiting covalent bond character and close to 1 for materials showing ionic type bond, $e$ is the charge of electron, $m$ is the mass of electron, $c$ is the velocity of light and $d n / d \lambda$ is the optical dispersion of the material. The wavelength dependence of Verdet coefficient for CdS thin films prepared with different rotational speeds is shown in Fig. 5. It is observed that the Verdet coefficient takes positive and negative values and mainly depends on the band gap in the negative part. 


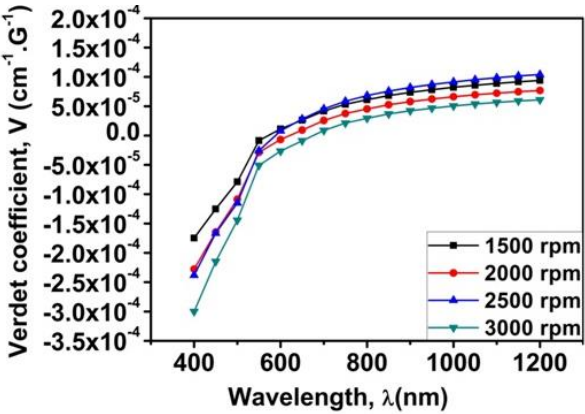

Fig. 5 Variation of Verdet coefficient dispersion for CdS thin films

\subsubsection{Determination of Dispersion Parameters}

The dispersion of refractive index in semiconductors has been analyzed using the concept of the single-oscillator model developed by Wemple and DiDomenico. From this model the energy parameters, singleoscillator energy $\left(E_{o}\right)$ and dispersion energy $\left(E_{d}\right)$ are introduced and the refractive index $(n)$ at any photon energy $(h v)$ is expressed by the WempleDiDomenico relationship [35],

$$
n^{2}=1+\frac{E_{o} E_{d}}{E_{o}{ }^{2}-(h v)^{2}}
$$

By plotting $\left(n^{2}-1\right)^{-1}$ versus $(h v)^{2}$ and fitting straight lines to the points as shown in Fig. 6, the oscillator parameters $E_{o}$ and $E_{d}$ are determined from the slope $\left(E_{o} E_{d}\right)^{-1}$ and the intercept on vertical axis $\left(E_{d} / E_{o}\right)$. The values of $E_{o}$ and $E_{d}$ are given in Table 4, it is noticed that these values decreased with the increase of rotational speed because of structural order and partial reconnection of atomic and molecular liaisons.

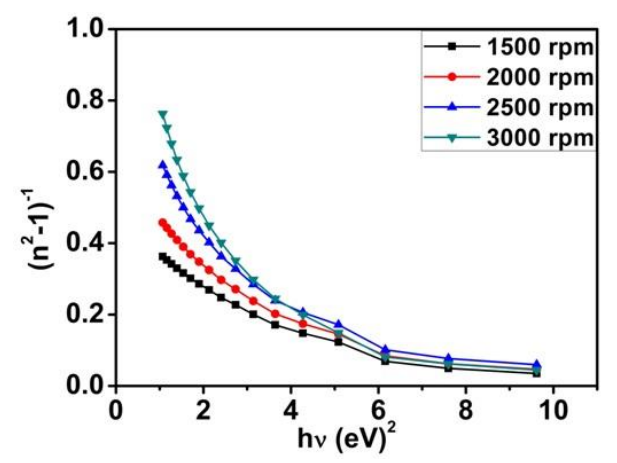

Fig. 6 Plot of $\left(\mathrm{n}^{2}-1\right)^{-1}$ vs $(\mathrm{h} v)^{2}$ for CdS thin films

Table 4 Optical dispersion parameters and non-linear optical parameters of CdS thin films

\begin{tabular}{lllll}
\hline Parameter & \multicolumn{5}{l}{ Rotational speed (rpm) } \\
\cline { 2 - 5 } & 1500 & 2000 & 2500 & 3000 \\
\hline $\mathrm{E}_{\mathrm{g}}(\mathrm{eV})$ & 2.65 & 2.58 & 2.49 & 2.46 \\
$\mathrm{E}_{\mathrm{o}}(\mathrm{eV})$ & 3.08 & 2.94 & 2.92 & 2.81 \\
$\mathrm{E}_{\mathrm{d}}(\mathrm{eV})$ & 7.71 & 6.53 & 5.03 & 4.13 \\
$\mathrm{M}_{-1}$ & 2.50 & 2.22 & 1.72 & 1.47 \\
$\mathrm{M}_{-3}\left(\mathrm{eV}^{-2}\right)$ & 0.26 & 0.25 & 0.20 & 0.18 \\
$\mathrm{n}_{\mathrm{o}}$ & 1.87 & 1.79 & 1.65 & 1.57 \\
$\varepsilon_{\infty}$ & 6.36 & 6.66 & 7.26 & 8.34 \\
$\mathrm{~N} / \mathrm{m}^{*}\left(10^{48} \mathrm{~cm}^{-3} \mathrm{~g}^{-1}\right)$ & 3.77 & 4.13 & 4.45 & 4.68 \\
$\omega_{\mathrm{p}}\left(10^{13} \mathrm{~Hz}\right)$ & 3.34 & 3.80 & 3.83 & 4.25 \\
$\tau\left(10^{14} \mathrm{~s}\right)$ & 3.00 & 2.63 & 2.61 & 2.35 \\
$\chi^{(1)} \mathrm{esu}$ & 0.20 & 0.18 & 0.14 & 0.12 \\
$\chi^{(3)}\left(10^{-13} \mathrm{esu}\right)$ & 2.66 & 1.66 & 0.66 & 0.32 \\
$\mathrm{n}_{2}\left(10^{-12} \mathrm{esu}\right)$ & 5.37 & 3.50 & 1.38 & 0.76 \\
\hline
\end{tabular}

From the analysis of $\left(n^{2}-1\right)^{-1}$ against $(h v)^{2}$, it allows to determine the static refractive index $\left(n_{o}\right)$ using the relation,

$$
n_{o}=\left(1+\frac{E_{d}}{E_{o}}\right)^{1 / 2}
$$

By extrapolating the Wemple-DiDomenico relation to the value of the incident photon energy $(h v)$ approaching zero. The calculated values of the static refractive index $\left(n_{0}\right)$ for all the films are reported in Table 4 . Using $E_{0}$ and $E_{d}$ obtained from the fitted transmittance spectra, $M_{-1}$ and $\mathrm{M}_{-3}$ moments of the optical spectra are determined from the following two equations [36],

https://doi.org/10.30799/jnst.238.19050210

$$
\begin{aligned}
& E_{o}{ }^{2}=\frac{M_{-1}}{M_{-3}} \\
& E_{d}{ }^{2}=\frac{M_{-1}{ }^{3}}{M_{-3}}
\end{aligned}
$$

These optical moments represent the measure of the average bond strength and single-oscillator approximation to the dielectric response of the material. The two moments $M_{-1}$ and $M_{-3}$ were calculated from the data of $E_{0}$ and $E_{d}$ are given in Table 4.

\subsubsection{Optical Dielectric Constant and Optical Conductivity}

The complex dielectric constant parameter provides the electronic structure of the material and helps in the design of highly efficient optoelectronic devices. The dependence of the refractive index $(n)$ on the real dielectric constant $\left(\varepsilon_{1}\right)$ is given by the Spitzer-Fan model [37],

$$
\begin{aligned}
& \varepsilon_{1}=n^{2}-k^{2}=\varepsilon_{\infty}-\left[\frac{e_{2}}{\pi c^{2}}\right]\left(\frac{N}{m^{*}}\right) \lambda^{2} \\
& \varepsilon_{2}=2 n k=\left(\frac{\varepsilon_{\infty} \omega_{p}^{2}}{8 \pi^{2} c^{3} \tau}\right) \lambda^{3}
\end{aligned}
$$

where $\varepsilon_{\infty}$ is the high-frequency dielectric constant, $e$ is the electronic charge, $c$ is the speed of light, $N / \mathrm{m}^{*}$ is the ratio of carrier concentration to the effective mass, $\omega_{p}$ is the plasma frequency and $\tau$ is the optical relaxation time. The plot of real dielectric constant $\left(\varepsilon_{1}\right)$ versus $\lambda^{2}$ for CdS thin films prepared with different rotational speeds are shown in Fig. 7(a). It is observed that the dependence of $\varepsilon_{1}$ on $\lambda^{2}$ is linear at longer wavelengths, the values of $\varepsilon_{\infty}$ and $N / m^{*}$ were deduced from the extrapolation of these plots to $\lambda^{2}=0$ and from the slope of the graphs. Fig. 7 (b) shows the variation of imaginary dielectric constant $\left(\varepsilon_{2}\right)$ with $\lambda^{3}$ for $\mathrm{CdS}$ thin films, it is found that $\varepsilon_{2}$ is lower than $\varepsilon_{1}$ which proves that the energy loss of light through thin films is low. Generally, the variation of dielectric constant with the rotational speed is attributed due to the defects such as stresses, voids, inhomogeneity, discontinuities, grain boundaries, etc. The real and imaginary part of dielectric constant of CdS thin films decreases with the increase of rotational speed from 1500 to 3000 due to the grain boundary defects. Similar trend in the variation of real and imaginary dielectric constant of CdS thin films prepared with different rotational speed is noticed, it is due to loss of energy which occurs due to the absorption of energy by free carriers present in the medium. It is noticed that the carrier concentration increases, band gap narrowing occurs due to many body effects and shifting of band edge towards the lower energy.
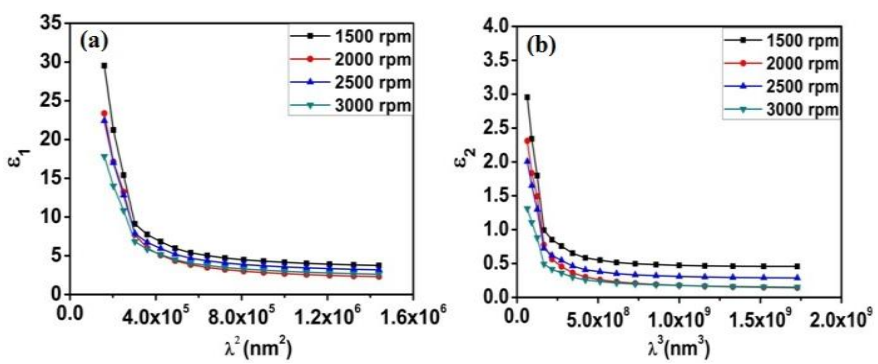

Fig. 7 Variation of (a) real part of the dielectric constant $\left(\varepsilon_{1}\right)$ versus $\lambda^{2}$ and (b) imaginary part of the dielectric constant $\left(\varepsilon_{2}\right)$ versus $\lambda^{3}$ for CdS thin films

The plasma frequency $\left(\omega_{p}\right)$ is related to the free carrier concentration to effective mass ratio $\left(\mathrm{N} / \mathrm{m}^{*}\right)$ from the following relation,

$$
\omega_{p}^{2}=\frac{4 \pi N e^{2}}{\varepsilon_{\infty} m^{*}}
$$

From the $\omega_{p}$, we have determined the relaxation time $\tau$ whose values are given in Table 4. It is observed that both $\varepsilon_{\infty}$ and $N / m^{*}$ values increased with increasing rotational rate from 1500 to $3000 \mathrm{rpm}$. The plasma frequency evaluated using Eq.(13) increases with increasing rotational speed (Table 4) which may be due to the increase in free carrier concentration.

The optical conductivity $\left(\sigma_{o p t}\right)$ describes the dissipation of electromagnetic energy in the material and proportional to absorption energy as,

$$
\sigma_{o p t}=\alpha n c / 4 \pi
$$


where $\alpha$ is the absorption coefficient, $n$ is the refractive index and $c$ is the velocity of light. Fig. 8 shows the variation of optical conductivity $\sigma_{\text {opt }}$ as a function of photon energy $h v$ for CdS thin films. The values of $\sigma_{\text {opt }}$ are found to be in the range of $1.8 \times 10^{13} \mathrm{~m}^{-1}$ to $1.17 \times 10^{15} \mathrm{~m}^{-1}$ for the CdS thin films prepared with rotational speed from 1500 to $3000 \mathrm{rpm}$. The increase in optical conductivity at high photon energies is due to the electron excited by photon energy. The overall high values of $\sigma_{\text {opt }}$ for all films increase the photo response behavior and make them suitable for optoelectronic applications.

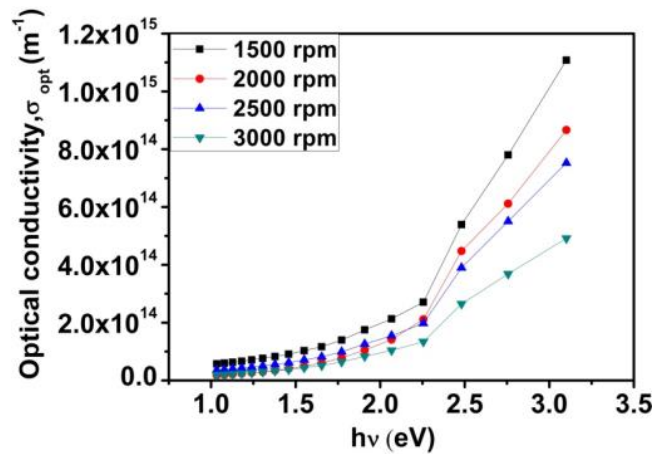

Fig. 8 Dependence of optical conductivity $\sigma_{\text {opt }}$ on the photon energy hv for CdS thin films

\subsubsection{Nonlinear Refractive Index}

When a high-intensity of light propagates through the medium, it causes nonlinear effects. The nonlinear refractive index $\left(n_{2}\right)$ is dependent on the incident intensity of light [38]. When the matter is exposed to electric field of the incident light, the polarization will not be proportional to electric field, and the change in polarizability has been extended by the terms which are proportional to square of electric field [39]. The $n_{2}$ is calculated in terms of Tichy and Ticha relation [40]

Tichy and Ticha relation is a combination of Miller's generalized rule and $n_{o}$ obtained from Wemple-DiDomenico model in the form,

$$
n_{2}=\frac{12 \pi \chi^{(3)}}{n_{o}}
$$

where $\chi^{(3)}$ is the third-order nonlinear susceptibility, which is given as

$$
\begin{aligned}
& \chi^{(3)}=A\left(\chi^{(1)}\right)^{4} \\
& \text { where } \chi^{(1)}=\frac{E_{d}}{4 \pi E_{o}}
\end{aligned}
$$

where $\mathrm{A}=1.7 \times 10^{-10}$ (for $\chi^{(3)}$ in esu). Then, $\chi^{(3)}$ is given as

$$
\chi^{(3)}=\frac{A}{(4 \pi)^{4}}\left(n_{o}^{2}-1\right)^{4}
$$

The values of $n_{2}, \chi^{(1)}$, and $\chi^{(3)}$ are given in Table 4 . It is observed that these values decreased with the increase of rotational speed from 1500 to $3000 \mathrm{rpm}$. These changes show that the film is suitable to change refractive index and oscillator parameters by varying rotational speed. Therefore, the films are found to be appropriate for designing nonlinear optical devices/optoelectronic devices.

\section{Conclusion}

CdS thin films were prepared on glass substrates by sol-gel spin coating method with rotational speed of 1500, 2000, 2500 and $3000 \mathrm{rpm}$. All the films exhibit cubic structure with preferential growth along the (111) plane confirmed by XRD analysis. The electrical resistivity of the films was found to be decreased with the increase of rotational speed. The optical transmittance of CdS thin films increases with the increase of rotational speed because of decrease in film thickness. The optical band gap of CdS thin films decreased from 2.65 to $2.46 \mathrm{eV}$ with the increase of rotational speed. The Verdet coefficient for the CdS thin films was calculated from the refractive index dispersion and it exhibited a spread negative range, which was dependent on the band gap energy. The dispersion of the refractive index of CdS thin films was analyzed by applying the Wemple-DiDomenico single oscillator model. It was found that the oscillator resonance energy $E_{o}$ and oscillator dispersion energy $E_{d}$ decreased with increasing rotational speed. In addition, nonlinear optical parameters like linear optical susceptibility $\chi^{(1)}$, nonlinear optical susceptibility $\chi^{(3)}$, and nonlinear refractive index $\mathrm{n}_{2}$ are also reported. The results in this work revealed a https://doi.org/10.30799/jnst.238.19050210 possibility of producing high-quality CdS thin films for futuristic nonlinear optical devices/ optoelectronic devices.

\section{Acknowledgements}

The authors would like to convey a special gratitude to CeNSE (Center of Nano Science and Engineering), Indian Institute of Science (IISc.,) Bangalore, India for providing the necessary facilities for this research work under INUP (Indian Nanoelectronics Users Program).

\section{References}

[1] Shadia J. Ikhmayies, Characterization of nanomaterial, J. Mineral. Met. Soc. 66 (2014) 46-60.

[2] F. Lisco, P.M. Kaminski, A. Abbas, J.W. Bowers, G. Claudio, et al., High rate deposition of thin film cadmium sulphide by pulsed direct current magnetron sputtering, Thin Solid Films 574 (2015) 43-51.

[3] G. Ojeda-Barrero, A.I. Oliva-Aviles, A.I. Oliva, R.D. Maldonado, M. Acosta, G.M Alonzo-Medina, Effect of the substrate temperature on the physical properties of sprayed-CdS films by using an automatized perfume atomizer, Mater. Sci. Semicond. Proc. 79 (2018) 7-13.

[4] M. Thambidurai, N. Muthukumarasamy, N. Murugan, S. Agilan, S. Vasantha, R. Balasundaraprabhu, Development of mathematical model for prediction and optimization of particle size in nanocrystalline CdS thin films prepared by solgel spin- coating method, Metall. Mater. Trans. B 41 (2010) 1338 -1345.

[5] S.H. Mousavi, M.H. Jilavi, T.S. Muller, P.W. de Oliveira, Formation and properties of cadmium sulfide buffer layer for CIGS solar cells grown using hot plate bath deposition, J. Mater. Sci.: Mater. Electron. 25 (2014) 2786-2794.

[6] M. Esmaeili-Zare, M. Behpour, Fabrication and study of optical properties on CdS semiconductor as buffer layer for $\mathrm{Cu}(\mathrm{In}, \mathrm{Ga}) \mathrm{Se}_{2}$ thin film solar cells, J. Mater. Sci.: Mater. Electron. 28 (2017) 10173-10183.

[7] Han Jun-feng, Fu Gan-hua, V. Krishnakumar, Liao Cheng, Wolfram Jaegermann, $\mathrm{CdS}$ annealing treatments in various atmospheres and effects on performances of CdTe/CdS solar cells, J. Mater. Sci.: Mater. Electron. 24 (2013) 2695-2700.

[8] P. Kumar, N. Saxena, R. Chandra, K. Gao, S. Zhou, et al., SHI induced enhancement in green emission from nanocrystalline CdS thin films for photonic applications, J. Lumin. 147 (2014) 184-189.

[9] Nam-Hoon Kim, Seung-Han Ryu, S. Hyo-Sup Noh, Woo-Sun Lee, Electrical and optical properties of sputter-deposited cadmium sulfide thin films optimized by annealing temperature, Mater. Sci. Semicond. Proc. 15 (2012) 125-130.

[10] Salah, Abdul-Jabbar Jassim, Abubaker A. Rashid Ali Zumaila, Gassan Abdella Ali Al Waly, Influence of substrate temperature on the structural, optical and electrical properties of CdS thin films deposited by thermal evaporation, Results Phys. 3 (2013) 173-178.

[11] M. Tsuji, T. Aramoto, H. Ohyma, T. Hibino, K. Omura, Characterization of CdS thin film in high efficient CdS/CdTe solar cells, J. Cryst. Growth. 214-215 (2000) $1142-1147$

[12] M.A. Mahdi, Z. Hassan, S.S. Ng, J.J. Hassan, S.K. Mohd Bakhori, Structural and optical properties of nanocrystalline CdS thin films prepared using microwaveassisted chemical bath deposition, Thin Solid Films 520 (2012) 3477-3484.

[13] S.D. Sartale, C.D. Lokhande, Growth of copper sulphide thin films by successive ionic layer adsorption and reaction (SILAR) method, Mater. Chem. Phys. 65 (2000) 63-67

[14] A.A. Yadav, E.U. Masumdar, Photoelectrochemical investigations of cadmium sulphide (CdS) thin film electrodes prepared by spray pyrolysis, J. Alloys Compd. 509 (2011) 5394-5399.

[15] A.A. Ziabari, F.E. Ghodsi, Growth, characterization and studying of sol-gel derived CdS nanoscrystalline thin films incorporated in polyethyleneglycol: Effects of post-heat treatment, Mater. Sol. Cells. 105 (2012) 249-262.

[16] M.A. Aegerter, R. Almeida, A. Soutar, K. Tadanaga, H. Yang, T. Watanabe, Coatings made by sol-gel and chemical nanotechnology, J. Sol. Gel. Sci. Tech. 47 (2008) 203-236.

[17] B.D. Cullity, Elements of X-ray diffraction, Addison-Wiley Reading, M.A., 1972.

[18] E. Akbarnejab, Z Ghorannevis, F. Abbasi, M. Ghorannevis, Investigation of annealing temperature effect on magnetron sputtered cadmium sulfide thin film properties, J. Theor. Appl. Phys. 11 (2017) 45-49.

[19] A. Kriper, E. Guneri, F. Gode, C. Gumus, T. Ozposan, The structural, electrical and optical properties of CdS thin films as a function of $\mathrm{pH}$ Mater. Chem. Phys. 129 (2011) 183-188.

[20] J. Santos Cruz, R.C. Perez, G.T. Delgado, O.Z. Angel, CdS thin films doped with metal- organic salts using chemical bath deposition, Thin Solid Films 518 (2010) 1791-1795.

[21] B. Hymavathi, B. Rajesh Kumar, T. Subba Rao, Post-annealing effects on surface morphological, electrical and optical properties of nanostructured $\mathrm{Cr}$-doped CdO thin films, J. Electron. Mater. 47 (2018) 503-511.

[22] M. Özta, M. Bedir, M.Y. Haciibrahimoglu, Y. Özdemir, S. Mert, Comparison of the Structural, electrical and optical properties of CdS films deposited by chemical bath deposition and spray pyrolysis, Nanomed. Nanotechnol. 3(000130) (2018) 1-8.

[23] Deokjoon Cha, Sunmi Kim, N.K. Huang, Study on electrical properties of CdS films prepared by chemical pyrolysis deposition, Mater. Sci. Eng. B: Solid State Mater. Adv. Technol. 106 (2004) 63-68.

[24] Fangyang Liu, Yanqing Lai, Jun Liu, Bo Wang, Sanshuang Kuang, et al., Characterization of chemical bath deposited CdS thin films at different deposition temperature, J. Alloy. Compd. 493 (2010) 305-308.

[25] N. Beji, M. Souli, M. Reghima, S. Azzaza, A. Safia, N.K. Turki, Effects of molybdenum doping and annealing on the physical properties of $\operatorname{~nn}_{2} \mathrm{O}_{3}$ Thin Films, J. Electron. Mater. 46 (2017) 6628-6638. 
[26] A.A. Yadav, M.A. Barote, E.U. Masundar, Studies on nanocrystalline cadmium sulphide (CdS) thin films deposited by spray pyrolysis, Solid State Sci. 12 (2010) 1173- 1177.

[27] Qiu Jijun, Jin Zhenggua, W. Weiging, L. Xiaoxin, C. Zhijie, Effect of annealing on structural, optical and electrical properties of CdS thin films grown by ILGAR, J. Wuhan Univ. Technol. Mater. Sci. Ed. 21 (2006) 88-91.

[28] B. Hymavathi, B. Rajesh Kumar, T. Subba Rao, Influence of sputtering power on structural, electrical and optical properties of reactive magnetron sputtered $\mathrm{Cr}$ doped CdO thin films, J. Mater. Sci: Mater. Electron. 28 (2017) 7509-7516.

[29] B. Rajesh Kumar, T. Subba Rao, Investigations on opto-electronical properties of DC reactive magnetron sputtered zinc aluminum oxide thin films annealed at different temperatures, Appl. Surf. Sci. 265 (2013) 169-175.

[30] J. Tauc, Amorphous and liquid semiconductors, Plenum Press, New York, 1974.

[31] B. Srinivasa Rao, V. Rajagopal Reddy, B. Rajesh Kumar, T. Subba Rao, Synthesis and characterization of nickel doped CdS nanoparticles, Int. J. Nano Sci. 11(1240006) (2012) 1-5.

[32] H. Metin, R. Esen, Annealing studies on CBD grown CdS thin films, J. Cryst. Growth 258 (2003) 141-148.

[33] D. Abdelkader, F. Chaffar Akkari, N. Khemiri, R. Miloua, F. Antoni, et al., Effect of $\mathrm{SnS}$ addition on the morphological and optical properties of $(\mathrm{SnS})_{\mathrm{m}}\left(\mathrm{Sb}_{2} \mathrm{~S}_{3}\right)_{\mathrm{n}}$ nano-rods elaborated by glancing angle deposition, Phys. B: Condens. Matter 546 (2018) 33-43.

[34] R. Hamrouni, N.E.H. Segmane, D. Abdelkader, A. Amara, A. Drici, et al., Linear and non-linear optical properties of $\mathrm{Sb}_{2} \mathrm{Se}_{3}$ thin films elaborated from nanocrystalline mechanically alloyed powder, Appl. Phys. A 124(861) (2018) 1-10.

[35] S.H. Wemple, M. DiDomenico, Behavior of the Electronic dielectric constant in covalent and ionic materials, Phys. Rev. B 3 (1971) 1338-1351.

[36] S.H. Wemple, M. DiDomenico, Optical dispersion and the structure of solids, Phys. Rev. Lett. 23 (1969) 1156-1160.

[37] C. Ravi Gobbiner, A.V. Muhammed Ali, D. Kekuda, Influence of oxygen flow rate on the structural, optical and electrical properties of $\mathrm{ZnO}$ films grown by $\mathrm{DC}$ magnetron sputtering, Appl. Phys. A 122(272) (2016) 1-9.

[38] W.G. Spitzer, H.Y. Fan, Determination of optical constants and carrier effective mass of semiconductors, Phys. Rev. 106 (1957) 882-890.

[39] B. Hymavathi, B. Rajesh Kumar, T. Subba Rao, Thickness dependent optical dispersion parameters and nonlinear optical properties of nanostructured $\mathrm{Cr}$ doped CdO thin films, Opt. Quant. Electron. 49(86) (2017) 1-13.

[40] H. Ticha, L. Tichy, Semi-empirical relation between non-linear susceptibility (refractive index), linear refractive index and optical gap and its application to amorphous chalcogenide, J. Optoelectron. Adv. Mater. 4 (2004) 381-386. 